\title{
Effect of crude and pure glycerol on biomass production and trehalose accumulation by Propionibacterium freudenreichii ssp. shermanii 1
}

\author{
Joanna Pawlicka-Kaczorowska ${ }^{\bowtie}$ and Katarzyna Czaczyk \\ Department of Biotechnology and Food Microbiology, Poznań University of Life Sciences, Poznań, Poland
}

The dairy propionibacteria, which are traditionally used for the production of Swiss cheeses, are able to synthesize valuable biomolecules, e.g. B group vitamins, propionic acid, and trehalose with unique chemical and physical properties. Both, dairy propionibacteria cells and trehalose, have found many applications as attractive and effective components in food, beauty and health care products. This study confirmed the ability of several strains from the Propionibacterium genus to create trehalose from glycerol. The research aimed to investigate the effect of crude and pure glycerol on biomass production and on trehalose accumulation by Propionibacterium freudenreichii ssp. shermanii 1 . The results indicated that the capacity for trehalose accumulation by Propionibacterium spp. was strain dependent. Propionibacterium freudenreichii ssp. shermanii 1 was able to grow on crude glycerol. For both, pure and crude glycerol, the highest amount of dry biomass leveled off at about $4 \mathrm{~g} / \mathrm{L}$. While the use of crude glycerol had no effect on the final concentration of biomass, it reduced the accumulation of trehalose in the cells. An increase in the concentration of carbon source $(2-8 \%)$ resulted in more than a 5 -fold rise in trehalose production. The highest trehalose concentration of $195.04 \mathrm{mg} / \mathrm{L}$ was obtained with cultures of the said strain supplemented to $8 \%$ with pure glycerol.

Key words: dairy propionibacteria, trehalose, biomass, crude glycerol

Received: 20 March, 2017; revised: 02 August, 2017; accepted:

02 August, 2017; available on-line: 02 November, 2017

e-mail: e-mail: joannap@up.poznan.pl:

\section{INTRODUCTION}

Over the last several years a large part of microbiological research has been focused on improving the bioproduction of health-promoting, functional and bioactive substances by microbial fermentation. The interest results from the fact that biologically active components are considered responsible for a broad range of beneficial changes in human and/or animal health (Hugenholtz et al., 2002; Zárate, 2012; PawlickaKaczorowska \& Czaczyk, 2016). The propionibacteria are Gram-positive, non-motile, non-sporing microorganisms with a high guanine-cytosine content in their DNA (53-68\%). The group of dairy propionibacteria, especially Propionibacterium freudenreichii ssp. shermanii, has a long history of safe use in human diet and animal feed that has contributed to their status of GRAS (generally recognized as safe) and QPS (qualified presumption of safety). They are used as the main ripening flora in the Swiss-type cheeses (Kujawski et al., 1996; Jan et al., 2000; Cardoso et al., 2004; Cousin et al., 2011). Other applications of the propionibacteria include their use as inoculants for silage. A growing number of studies is concerned with their potential as probiotics, which have been found to modulate intestinal microbiota, improve gut physiology, trigger apoptosis of colorectal cancer cells and exhibit immunomodulatory activity (Cardoso et al., 2004; Falentin et al., 2010; Cousin et al., 2011). The dairy propionibacteria are able to produce many functional compounds such as the B group vitamins, propionic acid, bacteriocins, conjugated linoleic acid, bifidogenic factors and trehalose (Poonam et al., 2012; Zárate, 2012; Pawlicka-Kaczorowska \& Czaczyk, 2016). Trehalose is a non-reducing sugar with a wide range of interesting properties (Argüelles, 2000; Higashiyama, 2002; Elbein et al., 2003; Cardoso et al., 2007; Teramoto et al., 2008; Drożdżyńska et al., 2009; Burek et al., 2015; Tien et al., 2016). In bacterial or yeast cells, trehalose acts as a source of energy and carbohydrates or a protectant against various stress factors like freezing, high osmotic pressure, oxygen radicals and heat (Argüelles, 2000; Chi et al., 2003; Elbein et al., 2003; Cardoso et al., 2007; Ruhal \& Choudhury, 2012a). This compound is a disaccharide formed by a 1,1-glycosidic linkage of two D-glucose molecules (Richardes et al., 2002; Elbein et al., 2003). Its physical and/or chemical properties include a low hygroscopic profile, as well as stability in wide ranges of $\mathrm{pH}$ and temperature (Richards et al., 2002). Trehalose is resistant to non-enzymatic browning, which is mainly caused by the Maillard reaction and caramelization. Furthermore, it protects biomolecules, such as starch, phospholipids and proteins, against degradation by cooling, heating or oxidation. It has been found to be able to preserve the organoleptic properties of dried or processed vegetables and fruits and to mask the malodors and malflavors of some pharmaceutical substances. The potential of trehalose as a preservative is exploited for the preservation of enzymes, antibodies, vaccines, cells as well as tissues and organs for transplantation. Other medically important properties include the suppression of osteoporosis and beneficial action in neurodegenerative disorders such as Alzheimer's, Huntington's and Parkinson's diseases. Trehalose has also proven capable of enhancing autophagic activity and being modified into novel inhibitors of cancer cell migration and invasion (Argüelles, 2000; Higashiyama, 2002; Schiraldi et al., 2002; Elbein et al., 2003; Cardoso et al., 2007; Teramoto et al., 2008; Drożdżyńska et al., 2009; Burek et al., 2015; Jiang et al., 2015; Tien et al., 2016). As a sugar of nutraceutical value, trehalose has been accepted as a safe food ingredient by the US Food and Drug Administra- 
tion and the European food regulation authorities. The above considerations demonstrate that the production of trehalose is of commercial importance since it opens new application opportunities in the food, cosmetics and pharmaceutical industries, as well as in medicine. Today, the microbiological production of pure trehalose (whether by bacteria or yeast) does not appear to be competitive against the industrial production of this disaccharide by using biotechnologies based on the enzymatic transformation of starch from maize or tapioca, developed by Hayashibara, a Japanese company. In 1995, this company had started the innovative production of trehalose that has led to an increase in the market availability of trehalose and a reduction in its price to about one per cent of the initial value (from $>\$ 200$ to $<\$ 3$ per kg) (Higashiyama, 2002; Teramoto et al., 2008; Burek et al., 2015). There has been a growing interest in the bioavailability of bioactive compounds of natural origin, such as plants or bacterial cells, as an alternative to chemical synthesis. More attention is also paid to the development of new food products offering health benefits and protection against diseases (Cousin et al., 2011; Zárate, 2012). Advancements in the knowledge of probiotics and bacterial cell factories generating bioactive substances have opened new opportunities for the application of microbial processes. Considering the increasingly beneficial effects of dairy propionibacteria on human well-being and on the health of some farm animals, the proven probiotic properties and the possibility of producing many functional compounds, an attractive proposal seems to be the development of a method for the growth of propionibacteria with an increased trehalose content allowing for the enrichment of biomass with an additional bioactive compound protecting the biomass against, e.g. lyophilisation or freezing, and extending the final product shelf life. In order to ensure the economical and attractive microbial production of valuable substances which falls within the scope of green chemistry, it is necessary to use renewable substrates such as industrial by-products. One of them, crude glycerol, is a principal waste of biodiesel production. It is estimated that the manufacture of biodiesel generates about $10 \%$ crude glycerol (Santibáñez et al., 2011; Dąbrowski et al., 2012; Yang et al., 2012). As predicted, biodiesel production has been increasing. In 2015, the world biodiesel market reached over 30 million tons, which supplied approximately 3 million tons of crude glycerol (Santibáñez et al., 2011; Yang et al., 2012; https://www.bp.com, 2016). A great variety of microorganisms can utilize crude glycerol as a carbon source, including the dairy propionibacteria (Rymowicz et al., 2009; Zhang \& Yang, 2009; Drożdżyńska et al., 2011; Kośmider et al., 2012; Ruhal \& Choudhury, 2012a; 2012b; Szymanowska-Powałowska, 2014). Despite presence of inhibitory components, such as salts and organic solvents present in biodiesel wastes, the course of propionic acid fermentation carried out with crude glycerol corresponds to that with pure glycerol (Zhang \& Yang, 2009; Kośmider et al., 2010; Ruhal \& Choudhury, 2012a; 2012b). The availability of crude glycerol offers a solution to the problem of alternative renewable feedstock for culturing dairy propionibacteria. Still, it is necessary to continue screening for the most suitable propionibacteria strains and to study the impact of different factors on propionibacteria cell functions. The main objective of this work was to evaluate the effect of crude and pure glycerol as a carbon source on the ability of Propionibacterium freudenreichii ssp. shermanii 1 to produce biomass with a high content of trehalose.

\section{MATERIALS AND METHODS}

Microorganisms. Propionibacterium freundenreichii ssp. shermanii DSM 4902 was received from the German Collection of Microorganisms and Cell Cultures (DSMZ). Three other strains, Propionibacterium freudenreichii ssp. shermanii 1, Propionibacterium acidipropionici 9 and Propionibacterium jensenii 16, came from a collection owned by the Department of Biotechnology and Food Microbiology, Poznań University of Life Sciences (Poznań, Poland). They were maintained on a liquid inoculum medium (Pędziwilk, 1975) supplemented to $20 \%$ with glycerol. Stock cultures were stored at $-20^{\circ} \mathrm{C}$.

Substrates. Pure and crude glycerol was used for cultivation. The pure glycerol was obtained from Chempur (Poland). The crude glycerol (partially refined and devoid of methanol) was provided as a by-product containing $86.7 \%$ pure glycerol from biodiesel production (Lotos, Poland).

Chemical analysis of crude glycerol. The Department of Chemistry at Poznań University of Life Sciences (Poland) analyzed the crude glycerol for the presence of selected chemical elements $(\mathrm{K}, \mathrm{Mg}, \mathrm{Ca}, \mathrm{Cu}, \mathrm{Cr}, \mathrm{Zn}, \mathrm{Na})$, which were determined by an AAS method using a Varian Atomic Absorption Spectrometer 200 series. The chloride ion concentration was established by a potentiometric method with the use of a TitroLine alpha plus automatic titrator (Schott Instruments, Germany). The glycerol and methanol were quantified by an HPLC method using an Agilent Technologies 1200 series chromatography system.

Media and cultivation. For inoculation, the medium contained $20 \mathrm{~g} / \mathrm{L}$ glucose, $5 \mathrm{~g} / \mathrm{L}$ casamino acid (Difco, USA), $10 \mathrm{~g} / \mathrm{L}$ casitone (Difco, USA), $1.76 \mathrm{~g} / \mathrm{L} \mathrm{K}_{3} \mathrm{PO}_{4}$ (POCH, Poland), $2.29 \mathrm{~g} / \mathrm{L} \mathrm{NaH_{2 }} \mathrm{PO}_{4} \times 2 \mathrm{H}_{2} \mathrm{O}$ (POCH, Poland), $0.3 \mathrm{mg} / \mathrm{L}$ biotin (Merck, Germany), $4 \mathrm{mg} / \mathrm{L}$ calcium pantothenate (Koch-Light, England), $5 \mathrm{mg} / \mathrm{L}$ $\mathrm{FeSO}_{4} \times 7 \mathrm{H}_{2} \mathrm{O}\left(\mathrm{POCH}\right.$, Poland), $2 \mathrm{mg} / \mathrm{L} \mathrm{CoSO}_{4} \times 6 \mathrm{H}_{2} \mathrm{O}$ (POCH, Poland), $10 \mathrm{mg} / \mathrm{L} \mathrm{MnCl}_{2} \times 4 \mathrm{H}_{2} \mathrm{O}(\mathrm{POCH}, \mathrm{Po}-$ land), $2 \mathrm{mg} / \mathrm{L} \mathrm{ZnCl}_{2}$ (POCH, Poland), and $0.2 \mathrm{~g} / \mathrm{L}$ $\mathrm{MgCl}_{2} \times 6 \mathrm{H}_{2} \mathrm{O}(\mathrm{POCH}$, Poland) (Pędziwilk, 1975).

The selected strains were retrieved from frozen glycerol stock cultures, transferred to the above-mentioned liquid inoculum medium and incubated overnight at $30^{\circ} \mathrm{C}$. The cultures (in an aliquot of $10 \%, \mathrm{v} / \mathrm{v}$ ) were next added to experimental fresh media to be tested for trehalose production. The composition of the medium used for strain selection was almost the same as that of the inoculum medium, differing only in the type and amount of carbon source. For this purpose, glucose was replaced by pure glycerol, which was added in an amount of $50 \mathrm{~g} / \mathrm{L}$ to the medium used to select the test strains. Following a 3-day incubation in $15 \mathrm{~mL}$ test tubes at $30^{\circ} \mathrm{C}$ under static conditions without $\mathrm{pH}$ regulation, the broths were collected and analyzed.

Next, the effect of the crude and pure glycerol as a carbon source on the ability of Propionibacterium freudenreichii ssp. shermanii 1 to synthesize trehalose was investigated. The fermentation was carried out in $150 \mathrm{~mL}$ flasks containing $100 \mathrm{~mL}$ of production media differing in the type of carbon source and proportional content $(2 \%, 5 \%$ and $8 \%, w / v)$. The composition of the basal medium for trehalose production was the same as that of the inoculum medium (without glucose). The cultures were incubated statically at $30^{\circ} \mathrm{C}$ and the $\mathrm{pH}$ was adjusted daily to 7 using $4 \mathrm{M} \mathrm{NaOH}$. Culture samples were 
Table 1. Comparison of trehalose and biomass production, substrate consumption and organic acid biosynthesis profile of the tested strains: Propionibacterium freudenreichii ssp. shermanii 1, Propionibacterium acidipropionici 9, Propionibacterium jensenii 16, Propionibacterium freundenreichii ssp. shermanii DSM 4902

\begin{tabular}{|c|c|c|c|c|c|c|}
\hline Bacteria & $\begin{array}{l}\text { Trehalose } \\
(\mathrm{mg} / \mathrm{L})\end{array}$ & $\begin{array}{l}\text { Biomass } \\
(\mathrm{g} / \mathrm{L})\end{array}$ & $\begin{array}{l}\text { Propionic } \\
\text { acid (g/L) }\end{array}$ & $\begin{array}{l}\text { Succinic } \\
\text { acid (g/L) }\end{array}$ & $\begin{array}{l}\text { Acetic acid } \\
(\mathrm{g} / \mathrm{L})\end{array}$ & $\begin{array}{l}\text { Glycerol con- } \\
\text { sumed (\%) }\end{array}$ \\
\hline $\begin{array}{l}\text { Propionibacterium freundenreichii ssp. } \\
\text { shermanii } 1\end{array}$ & $51.70 \pm 3.00$ & $1.03 \pm 0.06$ & $1.56 \pm 0.14$ & $0.21 \pm 0.03$ & $0.20 \pm 0.02$ & 13.82 \\
\hline Propionibacterium acidipropionici 9 & $50.49 \pm 3.33$ & $1.55 \pm 0.01$ & $3.45 \pm 0.28$ & $0.41 \pm 0.07$ & $0.19 \pm 0.08$ & 19.38 \\
\hline Propionibacterium jensenii 16 & $26.47 \pm 1.76$ & $1.53 \pm 0.04$ & $3.94 \pm 0.35$ & $0.28 \pm 0.10$ & $0.28 \pm 0.17$ & 22.20 \\
\hline $\begin{array}{l}\text { Propionibacterium freundenreichii ssp. } \\
\text { shermanii DSM } 4902\end{array}$ & $16.44 \pm 0.41$ & $0.98 \pm 0.09$ & $1.99 \pm 0.02$ & $0.25 \pm 0.03$ & $0.04 \pm 0.06$ & 8.27 \\
\hline
\end{tabular}

obtained at $0,24,72,120,168 \mathrm{~h}$ of the process. All fermentation experiments were run in three replicates.

Biomass quantification. Samples were collected at regular intervals and then were centrifuged $(4000 \times \mathrm{g})$. The collected pellet was washed with water. The washed cell pellet was suspended in $1 \mathrm{~mL}$ of distilled water and dried to a constant weight at $105^{\circ} \mathrm{C}$.

Extraction and quantification of trehalose. For trehalose extraction, $4 \mathrm{~mL}$ of broth from the culture medium were collected and centrifuged at $4000 \mathrm{~g}$ for $10 \mathrm{~min}$. The pellet was further washed with water. The washed cell pellet was suspended in $1.8 \mathrm{~mL} 80 \%$ methanol $(\mathrm{v} / \mathrm{v})$ and incubated at $60^{\circ} \mathrm{C}$ for $1 \mathrm{~h}$. After incubation, the sample was centrifuged. The supernatant was then filtered using a $0.45 \mu \mathrm{m}$ pore size LCR membrane (Merck Millipore, USA). The concentration of trehalose in the cell extract was analyzed by an HPLC method using an Agilent Technologies 1200 series chromatography system equipped with an automated sampler, a binary pump, a temperature control module and an IR detector. The analyses were performed isocratically at $40^{\circ} \mathrm{C}$ and a flow rate of $0.6 \mathrm{~mL} / \mathrm{min}$ on an Aminex HPX-87H $(300 \times 7.8 \mathrm{~mm})$ column (BIO-RAD, USA). The mobile phase was $5 \mathrm{mM} \mathrm{H}_{2} \mathrm{SO}_{4}$ and the injection volume equaled $50 \mu \mathrm{L}$. The qualitative and quantitative identification of trehalose was conducted using an external standard method referring to peak areas for calculations. The Agilent ChemStation software for LC 3D systems was employed.

Analytical methods for glycerol and acid analysis. Glycerol, propionic, acetic and succinic acids were quantified by an HPLC method. The culture broth was centrifuged (4000 g, $10 \mathrm{~min})$. The cell-free supernatant was diluted 5 times and filtered through a $0.45 \mu \mathrm{m}$ pore size MCE membrane (Merck Millipore, USA). The apparatus comprised an Agilent 1200 Series system equipped with an automated sampler, a binary pump, DAD and IR detectors. The analyses were performed isocratically at a flow rate of $0.6 \mathrm{~mL} / \mathrm{min}$ on an Aminex HPX-87H $(300 \times 7.8 \mathrm{~mm})$ column (BIO-RAD, USA) at a constant temperature of $40^{\circ} \mathrm{C} .1 \mathrm{mM}$ sulfuric acid was the mobile phase. The injection volume was $10 \mu \mathrm{L}$. External standards were used to identify peaks in chromatograms and peak areas were measured to determine sample concentrations. Data acquisition and analyses were conducted using the Agilent ChemStation software for LC 3D systems.

Osmometry. For each sample, $100 \mu \mathrm{L}$ of supernatant was placed in an Eppendorf tube for the measurement of osmolality using a cryoscopic osmometer (OS 3000 Marcel, Poland).

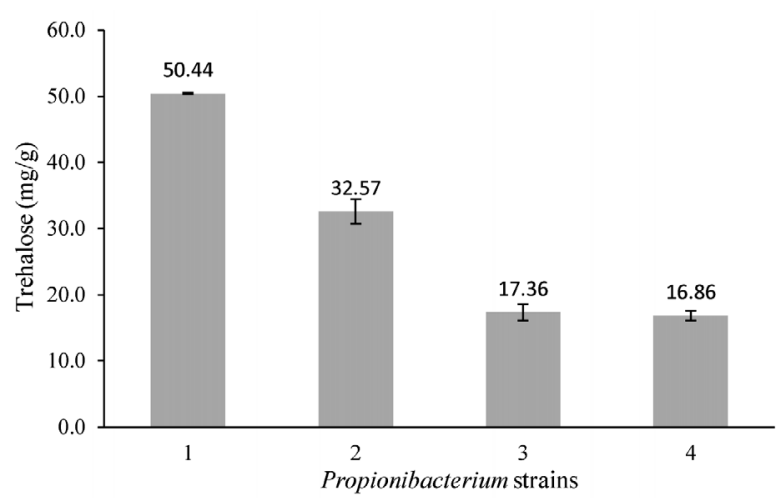

Figure 1. Comparison of trehalose yield relative to biomass (mg/g of biomass) in tested strains of Propionibacterium. 1 - Propionibacterium freundenreichii ssp. shermanii $1 ; 2$ - Propionibacterium acidipropionici 9; 3 - Propionibacterium jensenii 16; 4 Propionibacterium freundenreichii ssp. shermanii DSM 4902.

Statistical analysis. STATISTICA 13.1. PL (StatSoft, Poland) was used for all statistical analyses. One-way ANOVA and Tukey's tests were used for statistical evaluation of the data. The inference was performed at the significance level $\alpha=0.05$.

\section{RESULTS}

Before evaluating the impact of the crude and pure glycerol on biomass production and trehalose accumulation, the selection of strains was conducted. The tested strains of Propionibacterium were able to grow on the pure glycerol used as a carbon source in batch flask cultures,

Table 2. Maximum values of trehalose accumulation in Propionibacterium freudenreichii ssp. shermanii 1 for two types of carbon source at various concentrations

\begin{tabular}{clll}
\hline Carbon source & $\begin{array}{l}\text { Carbon source } \\
\text { concentration } \\
(\%)\end{array}$ & $\begin{array}{l}\text { Max. treha- } \\
\text { lose } \\
\text { accumula- } \\
\text { tion time }(\mathrm{h})\end{array}$ & $\begin{array}{l}\text { Max. trehalose } \\
\text { accumulation } \\
\text { (mg/g of bio- } \\
\text { mass) }\end{array}$ \\
\hline & 2 & 24 & $26.55 \pm 1.50$ \\
\hline Pure glycerol & 5 & 72 & $51.23 \pm 5.16$ \\
& 8 & 72 & $55.81 \pm 3.34$ \\
\hline & 2 & 24 & $17.38 \pm 1.76$ \\
\hline Crude glycerol & 5 & 72 & $15.54 \pm 1.51$ \\
\hline & 8 & 72 & $10.91 \pm 0.63$ \\
\hline
\end{tabular}



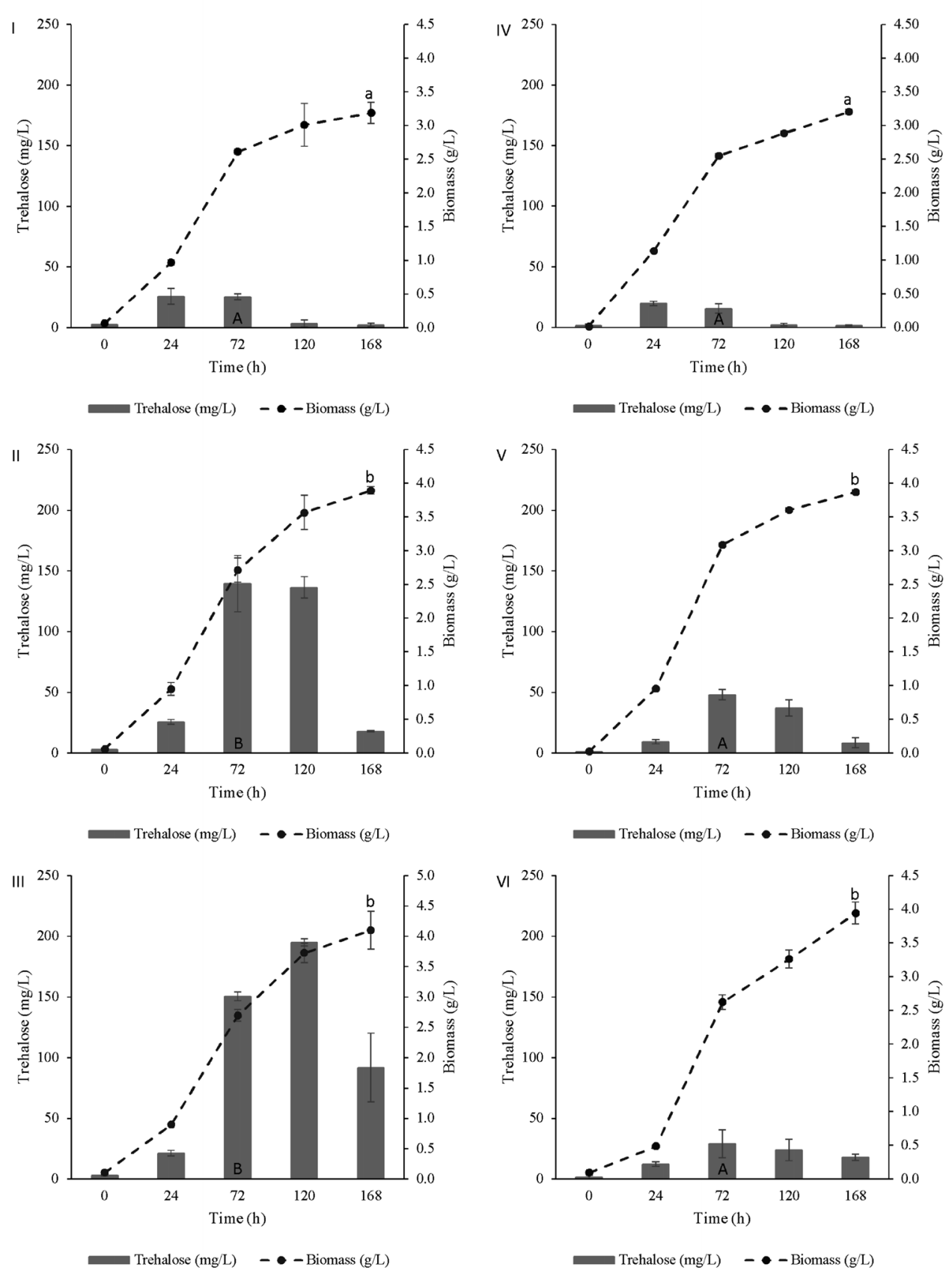

Figure 2. Trehalose $(\mathrm{mg} / \mathrm{L})$ and biomass $(\mathrm{g} / \mathrm{L})$ production obtained in fermentations with:

I - $2 \%$, II - 5\%, III - 8\% pure glycerol content, and IV - 2\%, V - 5\%, VI - 8\% crude glycerol content (carbon sources), using Propionibacterium freudenreichii ssp. shermanii 1 grown at $30^{\circ} \mathrm{C}$, with daily $\mathrm{pH}$ adjustment to 7 . Mean values of trehalose concentration (mg/L) obtained for the six tested variants of fermentation at $72 \mathrm{~h}$, in uppercase $(A-B)$, differing significantly $(p<0.05)$. Mean values of final biomass $(\mathrm{g} / \mathrm{L})$ obtained for the six tested variants of fermentation at $168 \mathrm{~h}$, in lowercase $(\mathrm{a}-\mathrm{b})$, differing significantly $(p<0.05)$.

without $\mathrm{pH}$ regulation or stirring. The main end-product was propionic acid in concentrations ranging from 1.56 to $3.94 \mathrm{~g} / \mathrm{L}$. The highest production of propionic acid was observed for Propionibacterium jensenii 16. Propionibacterium spp. also synthesized some quantities of other organic acids such as acetic and succinic acids (Table 1). The results show that the strains of Propionibacterium differed in trehalose production $(\phi<0.05)$ (Fig. 1 and Table 1). The strain Propionibacterium freudenreichii ssp. shermanii 1 was able to accumulate a larger amount of trehalose
(50.44 mg/g of biomass) than the other three strains and was therefore chosen for further research.

The potential for utilizing pure glycerol and crude glycerol as carbon sources in the biosynthesis of trehalose by Propionibacterium freudenreichii ssp. shermanii 1 was evaluated. A comparison of trehalose production using the two types of carbon source at various concentrations is shown in Table 2 and Fig. 2.

During static flask studies with the pure glycerol or crude glycerol as a carbon source, at $\mathrm{pH}$ adjusted daily 
Table 3. Biomass production, substrate consumption and organic acids biosynthesis profile of Propionibacterium freudenreichii ssp. shermanii 1 using different carbon sources at variable concentrations

\begin{tabular}{|c|c|c|c|c|c|c|}
\hline Carbon source & $\begin{array}{l}\text { Carbon source } \\
\text { concentration } \\
(\%)\end{array}$ & $\begin{array}{l}\text { Glycerol } \\
\text { consumed (\%) }\end{array}$ & Biomass (g/L) & Propionic acid (g/L) & Succinic acid (g/L) & Acetic acid $(\mathrm{g} / \mathrm{L})$ \\
\hline \multirow{3}{*}{ Pure glycerol } & 2 & $98.68 \pm 1.86$ & $3.19 \pm 0.16$ & $10.01 \pm 0.56$ & $0.92 \pm 0.11$ & $1.11 \pm 0.08$ \\
\hline & 5 & $59.43 \pm 3.11$ & $3.90 \pm 0.06$ & $12.67 \pm 0,28$ & $1.04 \pm 0.02$ & $1.21 \pm 0.06$ \\
\hline & 8 & $37.91 \pm 1.88$ & $4.10 \pm 0.31$ & $12.01 \pm 0.48$ & $1.26 \pm 0.08$ & $1.94 \pm 0.59$ \\
\hline \multirow{3}{*}{ Crude glycerol } & 2 & $98.91 \pm 1.54$ & $3.21 \pm 0.04$ & $9.29 \pm 0.11$ & $0.84 \pm 0.02$ & $1.01 \pm 0.03$ \\
\hline & 5 & $56.95 \pm 4.82$ & $3.87 \pm 0.03$ & $12.94 \pm 0.11$ & $1.08 \pm 0.11$ & $1.35 \pm 0.00$ \\
\hline & 8 & $36.53 \pm 0.07$ & $3.95 \pm 0.16$ & $11.71 \pm 0.44$ & $1.12 \pm 0.12$ & $1.30 \pm 0.23$ \\
\hline
\end{tabular}

to 7 , Propionibacterium freudenreichii ssp. shermanii 1 was able to accumulate trehalose in all tested media variants. The bacteria amassed greater amounts of trehalose $(p<0.05)$ in the media containing pure glycerol than in those with crude glycerol (Table 2). The highest trehalose yield relative to biomass was obtained at a pure glycerol concentration of $8 \%$ at $72 \mathrm{~h}$, reaching $55.81 \mathrm{mg} / \mathrm{g}$ of dry weight. Then, from $120 \mathrm{~h}$ to $168 \mathrm{~h}$ of culture, the level of trehalose decreased. At $168 \mathrm{~h}$ of culture, the yield of trehalose $(\mathrm{mg} / \mathrm{g}$ of biomass) was significantly lower $(p<0.05)$ and a 2.5 -fold fall in trehalose accumulation was observed. In regard to biomass, its production increased until $168 \mathrm{~h}$ (end of fermentation). For example, at $168 \mathrm{~h}$ in a culture in the medium containing $8 \%$ pure glycerol, the amount of dry biomass equaled $4.1 \mathrm{~g} / \mathrm{L}$ (Table 3). The course of that fermentation is given in Fig. 2. With respect to cultures grown on crude glycerol, the highest trehalose yield relative to biomass $(p<0.05)$ was obtained at a carbon source concentration of $2 \%$ at $24 \mathrm{~h}$, when the level of trehalose was $17.38 \mathrm{mg} / \mathrm{g}$ of dry weight corresponding to a biomass dry weight level of $1.14 \mathrm{~g} / \mathrm{L}$ (Fig. 2 and Table 2). At the end of fermentation $(168 \mathrm{~h})$, the yield of trehalose decreased and an over 30 -fold fall in trehalose accumulation, calculated relative to biomass, was observed $(p<0.05)$. The growth of the tested microorganisms did not depend on whether the pure or crude glycerol was used as a carbon source $(p<0.05)$. Moreover, an increase in the concentration of the carbon source (from $2 \%$ to $8 \%$ ) did not inhibit the growth of Propionibacterium freudenreichii ssp. shermanii 1 . The lowest level of biomass occurred in the media with a $2 \%$ glycerol content. The final biomass concentration slightly exceeded $3 \mathrm{~g} / \mathrm{L}$ (Fig. 2). It should be noted that the substrate consumption was close to $100 \%$ soon after $120 \mathrm{~h}$, during these variants of fermentation (data not shown). The $5 \%$ and $8 \%$ additions of carbon source resulted in a significantly higher biomass growth $(p<0.05)$. These amounts were more than $0.6 \mathrm{~g}$ greater (for media with $5 \%$ and $8 \%$ carbon source contents), as compared to cultures grown with a $2 \%$ substrate content (Fig. 2). In this case, at the end of fermentation $(168 \mathrm{~h})$, the glycerol was still present in the culture media (Table 3).

Despite impurities in the crude glycerol, the results show that biomass production was similar whether the pure or crude glycerol was used. It was noted that one or more components of the impurities contained in the carbon sources favorably affected the development of Propionibacterium freudenreichii ssp. shermanii 1. This was evidenced by observation of growth rate of the examined microorganism in the selected time ranges for the same concentration levels for the two types of carbon source. For example, comparing the growth rate in time from 0 to $24 \mathrm{~h}$ for a $2 \%$ carbon source content or in time from 0 to $72 \mathrm{~h}$ for a $5 \%$ carbon source content, a slightly faster growth was observed in the media with crude glycerol. Chemical analysis confirmed that the crude glycerol composition contained different chemical elements, including heavy metals (Table 4), and excluded the presence of methanol in the source used. The impurities of crude glycerol constituted about $13 \%$ of its total content and nearly $11 \%$ were sodium and chlorides. Considering this in the final count in the media, addition of $8 \%$ glycerol of biodiesel origin resulted in the concentration of sodium and chlorides at about $1 \%$.

The accumulation of trehalose did not directly correlate with the biomass increase (Fig. 2). However, the initial value of the carbon source concentration affected the process of trehalose accumulation in bacterial cells. During static flask studies with different pure glycerol concentrations in the media, higher trehalose concentrations and yields $(\mathrm{mg} / \mathrm{g}$ of biomass) were obtained in cultures with a greater carbon source content (Fig. 2). It was also found that in a culture grown at an increasing glycerol concentration, the highest content of trehalose $(\mathrm{g} / \mathrm{L})$ persisted longer in the course of fermentation (Fig. 2).

The highest trehalose concentration of 195.04 $\mathrm{mg} / \mathrm{L}$ was recorded for an $8 \%$ content of the pure glycerol, at $120 \mathrm{~h}$ of cultivation. The resulting value

Table 4. Composition of crude glycerol used in fermentations carried out by Propionibacterium freudenreichii ssp. shermanii 1

\begin{tabular}{lll}
\hline Compound & Units & Content \\
\hline Glycerol & $\%$ & 86.7 \\
\hline Methanol & $\mathrm{g} / \mathrm{L}$ & 0 \\
\hline Sodium & $\mathrm{g} / \mathrm{L}$ & $68.83 \pm 1.30$ \\
\hline Chlorides & $\mathrm{g} / \mathrm{L}$ & $40.67 \pm 0.23$ \\
\hline Potassium & $\mathrm{mg} / \mathrm{L}$ & $188.7 \pm 3.14$ \\
\hline Calcium & $\mathrm{mg} / \mathrm{L}$ & $75.46 \pm 0.73$ \\
\hline Magnesium & $\mathrm{mg} / \mathrm{L}$ & $66.47 \pm 0.97$ \\
\hline Zinc & $\mathrm{mg} / \mathrm{L}$ & $1.43 \pm 0.03$ \\
\hline Chromium & $\mu \mathrm{g} / \mathrm{L}$ & $333.23 \pm 5.09$ \\
\hline Copper & $\mu \mathrm{g} / \mathrm{L}$ & $296.93 \pm 4.41$ \\
\hline
\end{tabular}




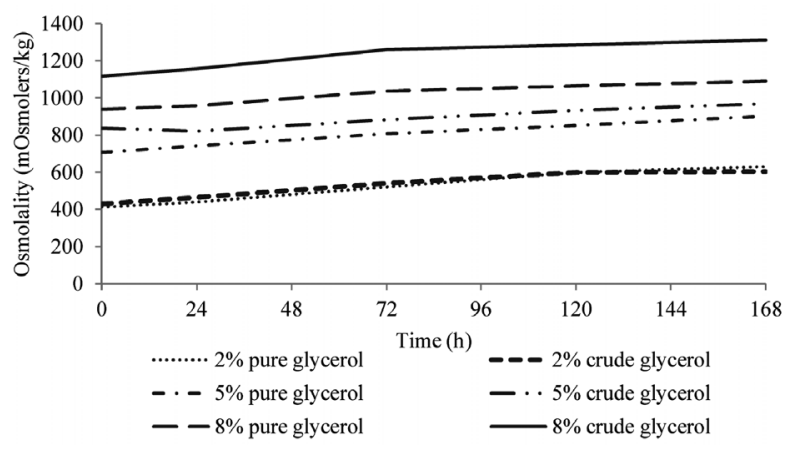

Figure 3. Osmolality of media differing in carbon source type and proportional content $(2 \%, 5 \%$ and $8 \%, w / v)$ during fermentations carried out by Propionibacterium freudenreichii ssp. shermanii 1.

exceeded about 7.0 times the trehalose concentration in fermentations carried out at an $8 \%$ crude glycerol content $(p<0.05)$. It must be stressed that in all tested variants the use of crude glycerol as the carbon source resulted in a lower production and trehalose accumulation with respect to biomass. Element analysis also revealed the presence of sodium, chlorides, potassium, calcium, magnesium, zinc, chromium and copper. A chemical characterization of a crude glycerol sample is given in Table 4. It is possible that the impurities in crude glycerol significantly affected the process of accumulation of trehalose by Propionibacterium freudenreichii ssp. shermanii 1 (Fig. 2).

Osmometric measurements confirmed that the addition of greater amounts of carbon source to the medium caused a rise in osmolality. Furthermore, it was found that the impurities present in glycerol increased the osmotic pressure of the media. Growth in media with crude glycerol was accompanied by a larger difference in osmolality relative to the media with a similar content of pure glycerol. Figures 2 and 3 show the culture responses to the medium osmolality depending on the type of carbon source. With pure glycerol present in the culture media, it was observed that an increase in osmolality corresponded to a higher trehalose accumulation in the bacterial cells. This positive correlation did not occur in the cultures grown with crude glycerol.

As shown in Table 3, Propionibacterium freudenreichii ssp. shermanii 1 utilized glycerol for the production of organic acids, such as propionic (the major end product), acetic and succinic acids. The experiments demonstrated that the greatest production of propionic acid was achieved with a $5 \%$ carbon source content in the culture media. The highest propionic acid concentrations were $12.94 \mathrm{~g} / \mathrm{L}$ and $12.67 \mathrm{~g} / \mathrm{L}$ using the crude and pure glycerol as substrates, respectively. An increase in the carbon source content (regardless of the type) from $5 \%$ to $8 \%$ in the culture media resulted in a lower production of propionic acid, oscillating within $12 \mathrm{~g} / \mathrm{L}$. A decrease in the substrate content from $5 \%$ to $2 \%$ resulted in a reduced production of propionic acid. The synthesis of propionic acid diminished by $21 \%$ when pure glycerol was used, and by $28 \%$ with crude glycerol when compared to fermentations run at a $5 \%$ content of the two types of carbon source. In all experiments, whether the pure or crude glycerol was used, irrespective of the amount added to the media, the production of acetic and succinic acids did not exceed $2 \mathrm{~g} / \mathrm{L}$ and $1.3 \mathrm{~g} / \mathrm{L}$, respectively (Table 3 ).

\section{DISCUSSION}

Microorganisms are generally known to be capable of synthesizing many valuable metabolites. This ability has been also displayed by the dairy propionibacteria, which indicates biochemical pathways of formation of compounds such as the B group vitamins, propionic, succinic, acetic, 5-aminolevulinic and/or conjugated linoleic acids, bacteriocins, bifidogenic growth stimulators and trehalose (Stjernholm, 1958; Czaczyk el al., 1997; Burgess et al., 2006; Furuichi et al., 2006; Gwiazdowska \& Trojanowska, 2006; Wang et al., 2006; Ruhal et al., 2011; Thierry et al., 2011; Kośmider et al., 2012; Poonam et al., 2012; Sonhom et al., 2012; Van Wyk \& Brtiz, 2012; Duarte et al., 2015; Jiang et al., 2015; Piwowarek \& Lipińska, 2015).

Although several species of bacteria can produce trehalose, only the dairy propionibacteria meet the food grade requirement among the strains tested for the ability to synthesize this disaccharide (Deborde et al., 1996; Argüelles, 2000; Poonam et al., 2012). Propionic acid bacteria can synthesize trehalose from various carbon sources, such as glucose, lactose or lactate (Stjernholm, 1958; Stjernholm \& Wood, 1960; Deborde et al., 1996; Deborde \& Boyaval, 2000; Cardoso et al., 2004). As reported by Deborde (1996) and Ruhal (2011, 2012a, $2012 \mathrm{~b})$, the dairy propionibacteria are able to also convert pure glycerol to trehalose.

The study presented here confirmed that bacteria of the Propionibacterium genus can accumulate trehalose. The ability to synthesize trehalose by species of Propionibacterium has previously been observed by others (Stjernholm, 1958; Deborde et al., 1996; Cardoso et al., 2004; Ruhal et al., 2011). The intracellular concentration of trehalose varied for the Propionibacterium strains used in this study. In the static flask cultures, the highest trehalose content in the cells of the tested bacteria was $5 \%$ whereas the lowest accumulation of this disaccharide was $1.7 \%$. Stjernholm (1958), who first identified trehalose in the Propionibacterium spp. cells, reported a similar content of trehalose in propionibacteria cells, ranging from $0.7 \%$ to $5.3 \%$ of dry weight.

On an industrial scale, some propionibacteria strains have been reported to be used for the production of vitamin $\mathrm{B}_{12}$ (Martens et al., 2002; Kośmider et al., 2012). As the cost of microbiological processes is generally still greater when compared to chemical synthesis, microbiological research has focused on reducing the cost of fermentation. The use of various agricultural and industrial wastes as a carbon source offers a green and economical solution for microbiological production. Many studies on the dairy propionibacteria have been done utilizing lowcost substrates, like cane molasses, whey, oil or crude glycerol.

Crude glycerol is a biodiesel manufacture by-product that can be converted as a raw material into value-added products, such as hydrogen (Sarma et al., 2012), 1,3-propanediol (Drożdżyńska et al., 2011), propionic acid (Kośmider et al., 2010), citric acid (Papanikolaou et al., 2002), succinic acid (Lee et al., 2001), single cell oil (Papanikolaou et al., 2008), vitamin $\mathrm{B}_{12}$ (Martens et al., 2002; Kośmider et al., 2012), erythritol (Rymowicz et al., 2009), ethanol (Choi et al., 2011), dihydroxyacetone (Claret et al., 1994) and trehalose (Ruhal et al., 2011).

In this study, the Propionibacterium frendenreichii ssp. shermanii 1 strain proved to accumulate the highest trehalose amount at the selection stage, was able to grow on crude glycerol, maintained profile of typical metabolites of propionic fermentation and the ability to accumulate treha- 
lose. To date, only one research team has reported on the suitability of crude glycerol for trehalose production (Ruhal et al., 2011; Ruhal \& Choudhury, 2012a; Ruhal \& Choudhury, 2012b). Several important differences exist between the study presented here and the findings of Ruhal and coworkers.

Firstly, it was observed that crude glycerol was more suitable for trehalose production in contrast to what was found in the study presented here (Ruhal et al., 2011; Ruhal \& Choudhury, 2012a). Consequently, in this study the trehalose concentrations and yields (relative to biomass) obtained with the media containing variable contents of crude glycerol $(2 \%, 5 \%$ and $8 \%, w / v)$ were lower in comparison with the concentrations and yields obtained in cultures when a corresponding content of pure glycerol was used as a carbon source.

Secondly, Ruhal and Choudhury collected data such that anaerobic static flask fermentation with crude glycerol induced in the Propionibacterium freudenreichii ssp. shermanii NCIM 5137 strain resulted in a low amount of biomass, finally not exceeding $0.25 \mathrm{~g} / \mathrm{L}$. At $72 \mathrm{~h}$ of fermentation, the results were nearly 7 times lower than those obtained at the same time of culture carried out in our study. Furthermore, while the authors (2011) tested the suitability of crude glycerol in a batch reactor under aerobic conditions, they observed a negative effect of crude glycerol on biomass production by Propionibacterium freudenreichii ssp. shermanii NCIM 5137. The authors suggested that the lower biomass concentration was attributable to the impurities present in crude glycerol. In our study, no effect of impurities on growth of the tested Propionibacterium frendenreichii ssp. shermanii 1 strain was observed. This may be explained by the fact that the chemical compositions of crude glycerol used in both studies were different. The composition of these waste products depended mainly on the kind of feedstock used for the production of biodiesel and the process technology $(\mathrm{NaOH}$ as a catalyst instead of $\mathrm{KOH}$ ) (Samul et al., 2014). Chemical analysis confirmed that the crude glycerol used in our study contained large quantities of sodium and chlorides. It should be stressed that the dairy propionibacteria are essential starters for the Swiss-type cheese manufacture. During cheese ripening, the growth of propionibacteria is influenced by several factors, among others by an approx. $2 \% \mathrm{NaCl}$ content, which seems to have a positive influence on their growth, as they occur in Swiss cheeses like Emmental in concentrations close to $10^{\circ}$ bacteria per 1 gram (Benjelloun et al., 2007; Cousin et al., 2011)

With regard to trehalose accumulation by the dairy propionibacteria, the current understanding of this phenomenon is far from complete, as it appears to be of a more complex metabolic nature, and so it needs further research (Ruhal et al., 2013). Due to its special physicochemical features, trehalose can protect the cell from various stress factors (Panek, 1985; Ribeiro et al., 1999; Argüelles, 2000; Elbein et al., 2003; Cardoso et al., 2007). A wide range of stressors may affect the process of accumulation of trehalose, e.g. the $\mathrm{pH}$ value, temperature, aeration and/or osmotic pressure. Argüelles (2000) reported that trehalose accumulation in cells is dependent on the media composition and is matched to the content of other organic solutes (betaine or $\mathrm{K}+$ ). In the study presented here, the concentration of glycerol had an impact on trehalose accumulation. When the pure glycerol content in the growth medium was increased in the range of $2-8 \%$, a statistically significant enhancement in trehalose synthesis was observed. This was consistent with the results of Cardoso and coworkers (2004) ob- tained for cultures of Propionibacterium freudenreichii ssp. shermanii NIZO B365 carried out at various concentrations of glucose. Comparing data on crude glycerol used in the research present here and on that reported by $\mathrm{Ru}-$ hal and coworkers (2011), two major differences need to be stressed. The crude glycerol used by Ruhal and coworkers was obtained in a different biodiesel production process where a different catalyst, such as $\mathrm{KOH}$, was added. Furthermore, before being used in fermentation, it was subjected to pre-treatment by separation of a significant part of the impurities (Ruhal et al., 2011; Ruhal \& Choudhury, 2012a).

No extensive studies have yet been conducted on the effect of individual nutrient components on trehalose production by Propionibacterium, nor any detailed levels of nutrient ingredients are known to cause cellular stress in the dairy propionibacteria. For bacterial cells, the lack of some compounds may be as stressful as their excess; for instance, the majority of organisms require minimal quantities of heavy metals which are toxic to them in greater concentrations (Oves et al., 2016).

With regard to the results reported in the paper presented here, the reason for a lower trehalose accumulation in the media with a crude glycerol content is probably due to the fact that the crude glycerol contained impurities comprised of compounds required by the tested strain for its balanced development.

As previously mentioned, it has been reported that the amount of trehalose and biomass produced by the propionibacteria varies and depends on a number of biological, chemical and physical factors (Kujawski et al., 1992; Deborde et al., 1996; Cardoso et al., 2004; Dalmasso et al., 2012; Ruhal et al., 2013; Pawlicka et al., 2015). Their co-occurrence may result in a different cell response, similarly to the effect of carbon source concentration changes and the impact of osmolality on trehalose accumulation in the presence or absence of chemical impurities (Figs. 2 and 3). It should be emphasized that the differing findings may result from the differences between the strains used, media compositions and fermentation conditions.

As has been demonstrated, the search for natural dairy propionibacteria strains may provide isolates with high intracellular levels of trehalose. By-products, such as crude glycerol, can be successfully applied as a carbon source for dairy propionibacteria cultures. At present, the lack of precise data on the impact of particular compounds, contained in the culture media, on trehalose accumulation by the dairy propionibacteria presents difficulties for the exploitation of industrial wastes and for the cost-effective production of biomass with a high content of trehalose. The authors of this study appreciate the need to focus their future work on the development and evaluation of the medium composition, as well as on the analysis of culture conditions, in order to better understand the biomass and trehalose production by the dairy propionibacteria.

\section{Conflict of interests}

The authors declare that they do not have any conflict of interests.

\section{Acknowledgements}

This research was funded from a subsidy designated for projects aimed at the development of young researchers and doctoral students in 2015, at the Faculty of Food Science and Nutrition, Poznan University of Life Sciences. 


\section{REFERENCES}

Argüelles JC (2000) Physiological roles of trehalose in bacteria and yeasts: a comparative analysis. Arch Microbiol 17: 217-224.

Benjelloun H, Rabe Ravelona M, Lebeault JM (2007) Characterization of growth and metabolism of commercial strains of propionic acid bacteria by pressure measurement. Eng Life Sci 7: 143-148. doi: 10.1002/elsc.200620180

Burek M, Waśkiewicz S, Wandzik I, Kamińska K (2015) Trehalose properties, biosynthesis and applications. CHEMIK 69: 469-476.

Burgess CM, Smid EJ, Rutten G, Van Sinderen D (2006) A general method for selection of riboflavin-overproducing food grade micro-organisms. Microb Cell Fact 24: 1-24. doi: 10.1186/1475-2859$5-24$

Cardoso FS, Castro RF, Burges N, Santos H (2007) Biochemical and genetic characterization of the pathways for trehalose metabolism in Propionibacterium frendenreichii, and their role in stress response. Microbiology 15: 270-280. doi: 10.1099/mic.0.29262-0

Cardoso FS, Gaspar P, Hugenholtz J, Ramos A, Santos H (2004) Enhancement of trehalose production in dairy propionibacteria through manipulation of environmental conditions. Int J Food Microbiol 91: 195-204. doi: 10.1016/S0168-1605(03)00387-8

Chi Z, Liu J, Ji J, Meng Z (2003) Enhanced conversion of soluble starch to trehalose by a mutant of Saccharomycopsis fibuligera sdu. I Biotechnol 120: 135-141.

Choi WJ, Hartono MR, Chan WH, Yeo SS (2011) Ethanol production from biodiesel-derived crude glycerol by newly isolated Kluyvera cryocrescens. Appl Microbiol Biotechnol 89: 1255-1264. doi: 10.1007/ s00253-010-3076-3

Claret C, Salmon JM, Romieu C, Bories A (1994) Physiology of Gluconobacter oxydans during dihydroxyacetone production from glycerol. Appl Microbiol Biotechnol 41: 359-365. doi: 10.1007/BF00221232

Cousin FJ, Mater DD, Foligne B, Jan G (2011) Dairy propionibacteria as human probiotics: a review of recent evidence. Dairy Sci \& Technol 91: 1-26. doi: 10.1051/dst/2010032

Czaczyk K, Trojanowska K, Grajek W (1997) The influence of a specific microelemental environment in alginate gel beads on the course of propionic acid fermentation. Appl Microbiol Biotechnol 48: 630-635. doi: 10.1007/s002530051107

Dalmasso M, Aubert J, Even S, Falentin H, Maillard MB, Parayre S, Loux V, Tanskanen J, Thierry A (2012) Accumulation of intracellular glycogen and trehalose by Propionibacterium freudenreichii under conditions mimicking cheese ripening in the cold. Appl Environ Microb 78: 6357-6364. doi: 10.1128/AEM.00561-12

Dąbrowski S, Zabłotna E, Pietrewicz-Kubicz D, Długołęcka A (2012) Screening of environmental samples for bacteria producing 1,3-propanediol from glycerol. Acta Biochim Pol 59: 353-356.

Deborde C, Boyaval P (2000) Interactions between pyruvate and lactate metabolism in Propionibacterium freudenreichii subsp. shermanii: in Vivo ${ }^{13} \mathrm{C}$ Nuclear Magnetic Resonance Studies. Appl Environ Microb 66: 2012-2020.

Deborde C, Corre C, Rolin DB, Nadal L, De Certaines JD, Boyaval P (1996) Trehalose biosynthesis in dairy Propionibacterium. J Magn Reson Anal 2: 297-304.

Drożdżyńska A, Leja K, Czaczyk K (2011) Biotechnological production of 1,3-propanediol from crude glycerol. BioTechnologia 92: 92-100.

Drożdżyńska A, Szymanowska D, Czaczyk K (2009) Optymalizacja procesu ekstrakcji trehalozy z komórek drożdży i określenie parametrów jej oznaczania techniką HPLC. Żymnośc Nauka Technologia Jakośc 66: 30-42.

Duarte JC, Valença GP, Moran PJ, Rodrigues JA (2015) Microbial production of propionic and succinic acid from sorbitol using Propionibacterium acidipropionici. AMB Express 5:13. doi: 10.1186/s13568-0150095-6

Elbein AD, Pan YT, Pastuszak I, Carroll D (2003) New insights on trehalose: a multifunctional molecule. Glycobiology 13: 17-27. doi: 10.1093/glycob/cwg047

Falentin H, Deutsch SM, Jan G, Loux V, Thierry A, Parayre S, Maillard MB, Dherbécourt J, Cousin FJ, Jardin J, Siguier P, Couloux A, Barbe V, Vacherie B, Wincker P, Gibrat JF, Gaillardin C, Lortal S (2010) The complete genome of Propionibacterium frendenreichii CIRM-BIA1T, a hardy Actinobacterium with food and probiotic applications. PloS one 5: e11748. doi: 10.1371/journal.pone.0011748

Furuichi K, Hojo K, Katakura Y, Ninomiya K, Shioya S (2006) Aerobic culture of Propionibacterium freudenreichii ET-3 can increase production ratio of 1,4-dihydroxy-2-naphthoic acid to menaquinone. $J$ Biosi Bioen. 101: 464-470. doi: 10.1263/jbb.101.464

Gwiazdowska D, Trojanowska K (2006) Antimicrobial activity and stability of partially purified bacteriocins produced by Propionibacterium freudenreichii ssp. freudenreichii and ssp. shermanii. Lait 86: 141-154. doi: 10.1051/lait:2006001

Higashiyama T (2002) Novel functions and applications of trehalose. Pure Appl Chem 74: 1263-1269. doi: 10.1351/pac200274071263

https://www.bp.com/content/dam/bp/pdf/energy-economics/statistical-review2016/bp-statistical-review-of-world-energy-2016-full-report.pdf
Hugenholtz J, Hunik J, Santos H, Samid E (2002) Nutraceutical production by propionibacteria. Lait 82: 103-112. doi: 10.1051/ lait:2001009

Jan G, Rouault A, Maubois JL (2000) Acid stress susceptibility and acid adaptation of Propionibacterium freudenreichii subsp. shermanii. Lait 80: 325-336. doi: 10.1051/lait:2000128

Jiang L, Cui H, Zhu L, Hu Y, Xu X, Li S, Huang H (2015) Enhanced propionic acid production from whey lactose with immobilized Propionibacterium acidipropionici and the role of trehalose synthesis in acid tolerance. Green Chem 17: 250-259. doi: 10.1039/C4GC01256A

Jiang YL, Li SX, Liu YJ, Ge LP, Han XZ, Liu ZP (2015) Synthesis and evaluation of trehalose-based compounds as novel inhibitors of cancer cell migration and invasion. Chem Biol Drug Des 86: 10171029. doi: $10.1111 /$ cbdd.12569

Kośmider A, Białas W, Kubiak P, Drożdżyńska A, Czaczyk K (2012) Vitamin $B_{12}$ production from crude glycerol by Propionibacterium freudenreichii ssp. shermanii: optimization of medium composition through statistical experimental designs. Bioresource Technol 105: 128-133. doi: 10.1016/j.biortech.2011.11.074

Kośmider A, Drożdżyńska A, Blaszka K, Leja K, Czaczyk K (2010) Propionic acid production by Propionibacterium freudenreichii ssp. shermanii using crude glycerol and whey lactose industrial wastes. Polish J of Environ Stud 19: 1249-1253.

Kujawski M, Rymaszewsi J, Cichosz G (1992) The effect of supplementation of selected metal ions on propionibacteria biomass field and production of voltatile fatty acids. Pol J Food Nutr Sci 3: 27-36.

Kujawski M, Rymaszewski M, Laniewska-Moroz L, Cichosz G (1996) Możliwości zastosowania bakterii fermentacji propionowej w przemyśle spożywczym. Przem Spoż 6: 35-37.

Lee PC, Lee WG, Lee SY, Chang HN (2001) Succinic acid production with reduced by product formation in the fermentation of Anaerobiospirillum succiniciproducens using glycerol as a carbon. Biotechnol Bioeng 72: 41-48.

Martens JH, Barg H, Warren MJ, Jahn D (2002) Microbial production of vitamin $\mathrm{B}_{12}$. Appl Microbiol Biotechnol 58: 275-285. doi: 10.1007/ s00253-001-0902-7

Oves M, Saghir Khan M, Huda Qari A, Nadeen Felemban M, Almeelbi T (2016) Heavy metals: biological importance and detoxification strategies. J Bioremediat Biodegrad 7: 1-15. doi: 10.4172/21556199.1000334

Panek A (1985) Trehalose metabolism and its role in Saccharomyces cerevisiae. I Biotechnol 3: 121-130. doi: 10.1016/0168-1656(85)90013-6

Papanikolaou S, Fakas S, Fick M, Chevalot I, Galiotou-Panayotou M (2008) Biotechnological valorisation of raw glycerol discharged after biodiesel (fatty acid methyl esters) manufacturing process: Production of 1,3-propanediol, citric acid and single cell oil. Biomass Bioenerg 32: 60-71. doi: 10.1016/j.biombioe.2007.06.007

Papanikolaou S, Muniglia L, Chevalot I, Aggelis G, Marc I (2002) Yarrowia lipolytica as a potential producer of citric acid from raw glycerol. I Appl Microbiol 92: 737-44.

Pawlicka J, Drożdżyńska A, Kośmider A, Czaczyk K (2015) The effect of phosphate buffer on biomass, propionic acid and trehalose production by Propionibacterium freudenreichii ssp. shermanii. EPISTEME Crasopismo Naukowo-Kulturalne 26: 85-93.

Pawlicka-Kaczorowska J, Czaczyk K (2016) Dairy propionibacteria - taxonomy, culture conditions and application. Post Mikrobiol 55: 367-380 (in Polish).

Pędziwilk F (1975) A simple plating method for the isolation and enumeration of Propionibacteria. Acta Alim Pol 25: 127-130.

Piwowarek K, Lipińska E (2015) Propionic acid bacteria useful in food industry. Przem Spoż 69: 26-30 (in Polish).

Poonam, Pophaly SD, Tomar SK, De S, Singh R (2012) Multifaceted attributes of dairy propionibacteria: a review. World J Microb Biot 28: 3081-3095. doi: 10.1007/s11274-012-1117-z

Ribeiro M, Leão L, Morais P, Rosa C, Panek A (1999) Trehalose accumulation by tropical yeast strains submitted to stress conditions. Antonie van Leeuwenhoek 75: 245-251.

Richards AB, Krakowka S, Dexter LB, Schmid H, Wolterbeek AP, Waalkens-Berendsen DH, Shigoyuki A, Kurimoto M (2002) Trehalose: a review of properties, history of use and human tolerance, and results of multiple safety studies. Food Chem Toxicol 40: 871-898.

Ruhal R, Aggarwal S, Choudhury B (2011) Suitability of crude glycerol obtained from biodiesel waste for the production of trehalose and propionic acid. Green Chem 13: 3492-3498. doi: 10.1039/C1GC15847C

Ruhal R, Choudhury B (2012a) Use of an osmotically sensitive mutant of Propionbacterium freudenreichii subsp. shermanii for the simultaneous productions of organic acids and trehalose from biodiesel waste based crude glycerol. Bioresource Technol 109: 131-139. doi: 10.1016/j. biortech.2012.01.039

Ruhal R, Choudhury B (2012b) Improved trehalose production from biodiesel waste using parent and osmotically sensitive mutant of Propionibacterium freudenreichii subsp. shermanii under aerobic conditions. I Ind Microbio Biotechnol 39: 1153-1160. doi: 10.1007/s10295012-1124-y 
Ruhal R, Kataria R, Choudhury B (2013) Trends in bacterial trehalose metabolism and significant nodes of metabolic pathway in the direction of trehalose accumulation. Microb Biotechnol 6: 493-502. doi: 10.1111/1751-7915.12029

Rymowicz W, Rywińska A, Marcinkiewicz M (2009) High-yield production of erythritol from raw glycerol in fed-batch cultures of Yarrowia lipolytica. Biotechnol Lett 31: 377-380. doi: 10.1007/s10529-008-9884-1

Samul D, Leja K, Grajek W (2014) Impurities of crude glycerol and their effect on metabolite production. Ann Microbiol 64: 891-898. doi: 10.1007/s13213-013-0767-x

Santibáñez C, Varnero MT, Bustamante M (2011) Residual glycerol from biodiesel manufacturing, waste or potential source of bioenergy: a review. Chil J Agr Res 71: 469-475. doi: 10.4067/S071858392011000300019

Sarma SJ, Brar SK, Sydney EB, Le Bihan Y, Buelna G, Soccol CR (2012) Microbial hydrogen production by bioconversion of crude glycerol: A review. Int J Hydrogen Energ 37: 6473-6490. doi: 10.1016/j.ijhydene.2012.01.050

Schiraldi C, Di Lernia I, De Rosa M (2002) Trehalose production exploiting novel approaches. Trends Biotechnol 20: 420-425.

Sonhom R, Thepsithar C, Jongsareejit B (2012) High level production of 5-amninolevulinic acid by Propionibacterium acidipropionici grown in low-cost medium. Biotechnol Lett 34: 1667-1672. doi: 10.1007/ s10529-012-0943-2

Stjernholm R (1958) Formation of trehalose during dissimilation of glucose by Propionibacterium. Acta Chem Scand 12: 646-649.

Stjernholm R, Wood HG (1960) Trehalose and fructose as indicators of metabolism of labelled glucose by propionic acid bacteria. J Biol Chem 235: 2753-2756.

Szymanowska-Powałowska D (2014) 1,3-Propanediol production from crude glycerol by Clostridium butyricum DSP1 in repeated batch. Electron J Biotechnol 17: 322-328. doi: 10.1016/j.ejbt.2014.10.001
Teramoto N, Sachinvala ND, Shibata M (2008) Trehalose and trehalose-based polymers for environmentally benign, biocompatible and bioactive materials. Molecules 13: 1773-1816. doi: 10.3390/molecules13081773

Tien NT, Karaca I, Tamboli IY, Walter J (2016) Trehalose alters subcellular trafficking and the metabolism of the Alzheimer-associated amyloid precursor protein. I Biol Chem 291:10528-1040. doi: 10.1074/jbc.M116.719286

Thierry A, Deutsch SM, Falentin H, Dalmasso M, Cousin FJ, Jan G (2011) New insights into physiology and metabolism of Propionibacterium freudenreichii. Int J Food Microbiol 149: 19-27. doi: 10.1016/j.ijfoodmicro.2011.04.026

Van Wyk J, Brtiz JT (2012) A rapid high-performance liquid chromatography (HPLC) method for the extraction and quantification of folates in dairy products and cultures of Propionibacterium freudenreichii. Afr J Biotechnol 11: 2087-2098. doi: 10.1051/dst/2009055

Wang L, Lv J, Chu Z, Cui Y, Ren X (2006) Productionn of conjugated linoleic acid by Propionibacterium freudenreichii. Food Chem 103: 31-318. doi: 10.1016/j.foodchem.2006.07.065

Yang F, Hanna MA, Sun R (2012) Value-added uses for crude glycerol - a byproduct of biodiesel production. Biotechnol Biofuels 5: 1-10. doi: 10.1186/1754-6834-5-13

Zárate G (2012) Dairy propionibacteria: less conventional probiotic to improve the human and animal health. In Probiotic in Animals, Rigobelo E, pp 153-202. InTech, Rijeka. doi: 10.5772/50320

Zhang A, Yang ST (2009) Propionic acid production from glycerol by metabolically engineered Propionibacterium acidipropionici. Process Biochem 44: 1346-1351. doi: 10.1016/j.procbio.2009.07.013 